\title{
FORMAÇÕES SOCIO-ESPACIAIS: PROGRESSO TÉCNICO NO ESPAÇO URBANO E AGRÁRIO
}

\author{
Socio-spatial formations: technical progress \\ in urban and agricultural spaces \\ Formaciones socio- espacial: progresso tecnico \\ con espacio urbano y agricola
}

\section{Carlos José Espindola,}

Doutor em Geografia Humana (USP) e Pós doutor em Geografia (UAB). Docente do Programa de Pós Graduação em Geografia da Universidade Federal de Santa Catarina e Docente do Departamento de Geociências da UFSC. Rua capitão Euclides de Castro 265, apto 204. Coqueiros Florianopolis-SC CEP 88080-010.E.mail: carlos.espindola@ufsc.br

\section{Tania Maria Fresca,}

Doutorado em Geografia pela Universidade de São Paulo. Docente no Programa de Pós-graduação em Geografia da Universidade Estadual de Londrina (UEL). Universidade Estadual de Londrina, Centro de Ciências Exatas; Rodovia Celso Garcia Cid, Pr 445, Km 380, Campus Universitário; Cx. Postal 10.011, CEP 86.057-970,_Londrina - PR. E.mail: tania_geografia@yahoo.com.br.

\section{Cesar Augusto Martins,}

Pos doutor pela Universitat Autònoma de Barcelona; Docente no Programa de Pós-graduação em Geografia da Universidade Federal do Rio Grande (FURG). Universidade Federal do Rio Grande, ICHI Av. Itália km 8 Campus Carreiros Rio Grande-Rs 96203-900; E.mail: cavilamartins@yahoo.com.br

\section{Fernando Santos Sampaio,}

Doutor em Sensoriamento Remoto pelo Instituto Nacional de Pesquisas Espaciais. Bolsista de Produtividade em Pesquisa do CNPq - Nível 2 - CA GC - Geociências. Universidade Federal de Santa Maria, Departamento de Engenharia Florestal - CESNORS/UFSM. Campus do CESNORS - UFSM sala 59 bl 4. Faguense, CEP: 98400000 - Frederico Westphalen, RS - Brasil.E.mail:breunig@ufsm.br

\section{José Messias Bastos}

Doutorado em Ciências, opção Geografia Humana pela Universidade de São Paulo - USP.

Docente no Programa de Pós-graduação em Geografia da Universidade Federal de Santa Catarina (UFSC).

Rua: Joe Collaço, 126 - Bairro Córrego Grande - Florianópolis-SC -CEP 88037-010

E.mail: jbastos57@gmail.com 


\section{RESUMO}

A crise da economia mundial iniciada em 1973 trouxe para o debate as questões referentes à inovação tecnológica, como uma das possibilidades de retomada do crescimento econômico a lá Schumpeter. Contudo, essa possibilidade depende do estágio de desenvolvimento das forças produtivas, das relações de produção e do arranjo institucional das diferentes formações sócio espaciais. Essas formações ao receberem determinações da dinâmica do sistema capitalista mundial, forçam os seus agentes sociais a adotarem estratégias defensivas e/ou ofensivas, que resultam em práticas espaciais diversas. São estratégias que estão diretamente vinculadas à implementação, por parte do Estado, de medidas político institucionais. Diante desse pressuposto, o objetivo deste texto é o de apresentar as principais contribuições dos trabalhos inseridos no GT: "Formações Sócio-Espaciais: Progresso Técnico no Espaço Urbano e Agrário".

Palavras-chave: Formações sócio-espaciais; Progresso Técnico; Espaço urbano e Rural; Dinâmica Capitalista.

\section{ABSTRACT}

The world economic crisis, in 1973 brought to debate issues of technological innovation as one of the possibilities of economic growth resumption related to Schumpeter. However, that possibility depends on the development stage of productive forces, production relations and the institutional arrangement of different socio-spatial formations. Such formations when receiving dynamics determinations of the world capitalist system, force their social agents to adopt defensive and/or offensive strategies that result in different spatial practices. They are strategies directly linked to the implementation of institutional political measures by the State. Given that assumption, the paper aims to present the main contributions of works inserted in the GT: "SocioSpatial Formations: Technical Progress in Urban and Agricultural Spaces".

Keywords: Socio-spatial formations. Technical progress. Rural and urban spaces. Capitalist dynamics.

\section{RESUMEN}

La crisis económica mundial comenzó en 1973 trajo al debate los temas de la innovación tecnológica como una de las posibilidades de reanudación del crecimiento económico a lá Schumpeter. Sin embargo, esta posibilidad depende de la etapa de desarrollo de las fuerzas productivas de las relaciones de producción y el arreglo institucional de las diferentes formaciones espaciales socio. Estas formaciones para recibir las determinaciones de la dinámica del sistema capitalista mundial, obligando a sus trabajadores sociales a adoptar estrategias defensivas y/o ofensivos que dan lugar a diferentes prácticas espaciales. Son estrategias que están directamente vinculadas a la aplicación por el Estado, las medidas políticas institucionales. Dado este supuesto, el objetivo de este trabajo es presentar las principales aportaciones de la obra inscrita en el GT: " Formaciones Socio-Espaciais Progreso Técnico en el Espacio Urbano y Agrícola"

Palabras clave: formaciones socio - espaciales; progreso técnico; zonas urbanas y rurales; La dinámica capitalista. 


\section{INTRODUÇÃO}

O objetivo geral deste artigo é apresentar as principais contribuições dos trabalhos apresentados no Grupo de Trabalho denominado "Formações sócio-espaciais: Progresso Técnico no Espaço Urbano e Agrário”, durante a realização do XI Encontro Nacional da Anpege, na cidade de Presidente Prudente - SP, em outubro de 2015.

A categoria de formação sócio-espacial decorre da ideia de formação econômicosocial elaborada por Marx e Engels, e sistematizada por Lênin (1955), para compreender o conjunto da história e o desenvolvimento de uma dada sociedade. Lênin retoma a noção para analisar uma sociedade concreta e atacar o objetivismo (caráter apolítico das ciências) e o subjetivismo (que colocava os problemas das ciências em razão da consciência).

Sua preocupação era romper com o marxismo da II Internacional (Plekhanov e Kaustky), assentada no economicismo, que associava a categoria de formação social ao de modo de produção. A sociedade russa, objeto de análise de Lênin, desenvolvia em seu seio o capitalismo, o campesinato, a pequena burguesia e a nobreza feudal (LEFEBVRE, 1969). Trata-se, portanto, de uma busca pela compreensão histórica (continuidade e descontinuidade) das esferas sociais (SERENI, 1976).

Didaticamente, a formação social é uma realidade concreta, que nasce, evolui e muda historicamente de forma dialética. O econômico é composto pelas forças produtivas, isto é, pelas relações entre o homem e a natureza. O social articula as relações entre os homens (as relações de produção). Em seu conjunto, essa categoria “[...] se coloca inequivocamente no plano da história, que é o da totalidade e da unidade de todas as esferas (estruturais, supraestruturais e outras), da vida social na continuidade e ao mesmo tempo na descontinuidade do seu desenvolvimento histórico" (SERENI, 1976, p. 71).

Santos (1977) salienta que a formação econômica e social é indissociável da realidade histórico-concreta, geograficamente localizada. Assim, a noção de formação econômica e social adquire o status de formações históricas e geograficamente localizadas, isto é, formações socio-espaciais. Mas, qual a escala de análise para a utilização da categoria de formação socio-espacial?

A categoria/conceito de formação socio-espaciais será utilizada para análise na escala nacional e regional, pois as diferenciações espaciais das formações sociais são constituídas por particularidades histórico-genéticas das relações de produção e das forças produtivas em um ambiente social e geograficamente dado, pois “[...] a análise geográfica dos fenômenos requer a consideração da escala em que eles são percebidos” (CASTRO, 1992, p. 21). 
O nascimento, a evolução e a transformação de uma formação sócio-espacial estão diretamente relacionados ao desenvolvimento das forças produtivas, domínio do homem sobre a natureza ${ }^{1}$. Não se trata aqui de um determinismo tecnológico, no qual as forças tecnológicas são o fator decisivo na geração das mudanças sociais e econômicas, mas sim de destacar, conforme Santos (1996, p. 67), que “[...] a base técnica da sociedade e do espaço constitui, hoje, um dado fundamental da explicitação histórica, já que a técnica invadiu todos os aspectos da vida humana, em todos os lugares". Ainda, de acordo com Santos (1996, p. 127),

[...] o conteúdo técnico-científico do espaço permite, em áreas cada vez mais extensas, a produção de um mesmo produto em quantidades maiores e em tempo menor, rompendo os equilíbrios persistentes e impondo outros, do ponto de vista da quantidade e da qualidade da população, dos capitais empregados, das formas de organização, das relações sociais, etc.

Diante do exposto, os coordenadores do GT, após avaliarem os textos recebidos e assistir à apresentação de cada um desses trabalhos no XI Encontro Nacional da ANPEGE, elaboraram o presente artigo com os resultados obtidos. Mais que isso, pois, em realidade, articulam os trabalhos com as ideias centrais presentes na ementa do GT, de modo a terse um quadro de caminhos das discussões realizadas. Operacionalmente, dividiram-se os trabalhos de acordo com as temáticas urbanas e rurais, procurando relacioná-los à dinâmica capitalista contemporânea caracterizada pela: (1) financeirização da economia; (2) expansão do comércio internacional; (3) retardamento do processo de "destruição criadora" a lá Schumpeter; (4) intensa oligopolização da economia com o aceleramento das fusões e aquisições, e greenfield projects (investimentos novos). Esses elementos do sistema econômico contemporâneo promoveram reestruturações técnico-econômicas (FREEMAN, 1987), que tenderam a criar mudanças estruturais, institucionais, sociais e territoriais.

\section{O PROGRESSO TÉCNICO}

Os trabalhos apresentados no GT articularam a ideia de progresso técnico no desenvolvimento urbano e rural. O progresso técnico compreende "[...] certos tipos de conhecimento que tornam possível produzir, a partir de uma dada quantidade de recursos, (1) um maior volume de produto ou (2) um produto quantitativamente superior" (ROSEMBERG, 2006, p. 18).

\footnotetext{
A história da humanidade é inseparável da história do progresso técnico (ROSEMBERG, 2006). O esforço do homem em desenvolver técnicas deriva da necessidade de aumentar o seu domínio e controle sobre a natureza. Ao agir sobre a natureza, ele não só a transforma como também modifica a sua própria natureza.
} 
O progresso técnico apresenta uma natureza caracterizada pela continuidade e descontinuidade, um ritmo associado ao seu dinamismo e uma direção relacionada aos melhoramentos, adaptações e rupturas². Partindo do pressuposto de que o progresso técnico é fruto da combinação do dinamismo econômico, da ciência e das estruturas sociais, os trabalhos apresentados de forma direta e/ou indireta, articularam a importância das instituições ${ }^{3}$. É, pois, nesse sentido, que foram utilizados os referenciais teóricos neoshumpeterianos que destacam o path dependency (competências acumuladas historicamente), o ambiente e a seleção, que tendem a validar ou não uma inovação realizada por meio de sua aplicação/difusão.

Articulando progresso técnico com dinamismo econômico e instituições, o GT utilizou ainda a ideia de ciclos da economia mundial desenvolvidos por Kondratieff. A economia mundial, no decorrer de longos períodos históricos, experimentou significativas variações em seu desempenho agregado, desenvolvendo-se em ciclos de 50 anos, divididos em fases expansivas (25 anos) e fases depressivas (25 anos).

Na hipótese de Kondratieff, a base material desses ciclos é

[...] o desgaste, a substituição e a expansão de bens de capital fixos que exigem um longo período de tempo e enormes gastos para serem produzidos. A substituição e expansão destes bens não se dão suavemente, mas sim em saltos. O período de produção crescente de bens de capital corresponde à fase de expansão reciprocamente, a desaceleração deste processo causa um movimento de elementos econômicos em direção ao nível de equilíbrio ou abaixo dele (ROSEMBERG; FRISCHTAK, 1983) ${ }^{4}$.

2 No entendimento de Schumpeter $(1984 ; 1985)$, a inovação é o "fenômeno fundamental" da vida econômica capitalista, que produz o desenvolvimento, o progresso e a evolução econômica. A inovação está no centro da instabilidade cíclica como do crescimento econômico. Trata-se de um processo denominado de destruição criativa. As inovações podem ocorrer da seguinte forma: (a) introdução de um novo bem aos consumidores ou então de nova qualidade de um certo bem; (b) introdução de um novo processo de produção processo ainda não experimentado; (c) abertura de um novo mercado, ou seja, um mercado em que o produto de determinada indústria nunca tivera acesso antes; $\mathrm{d}$ ) descoberta de uma nova fonte de matéria-prima ou de produtos semiacabados; e) reorganização de uma indústria qualquer, como a criação ou a ruptura de uma posição de um monopólio.

3 O papel das instituições no desempenho econômico foi objeto de análise de Thorstein Veblen (1982). Os novos estudos da economia institucional, destacam novos conceitos como custos de transação, limitações informais, regras formais, direitos de propriedade, aprendizagem, etc.

${ }_{4}$ Kondratieff e Oparin (1928, p. 60-61) apud Rosemberg e Frischtak (1983, p. 677). Em termos gerais, a economia desenvolveu-se em quatro grandes ciclos econômicos de longa duração, a saber: $1^{\circ}$ ciclo: fase a: 1790 - 1815 / fase b: 1815 - 1847; $2^{\circ}$ ciclo: fase a: 1847 - 1873/ fase b: 1873 - 1896; $3^{\circ}$ ciclo: fase a: 1896 - 1920/fase b: 1920 - 1948; $4^{\circ}$ ciclo: fase a: 1948 - 1973/ fase b: 1973 - 19--. A fase ascendente de um ciclo implica a ocorrência simultânea de uma explosiva fase de crescimento em novas e importantes indústrias e tecnologias. Esse movimento ascendente torna-se possível a partir da realização prévia e bem-sucedida, não importando as datas, de certas inovações básicas anteriores. Na fase descendente, estimula-se a busca por inovações e mudanças técnicas poupadoras de mão de obra e de outros custos. Porém, as defasagens temporais envolvidas significam que pode passar um período de cinco a vinte anos antes que os efeitos completos de tais mudanças técnicas se façam sentir de modo geral no sistema. Existem defasagens tanto no sistema de P \& D quanto na implementação das inovações disponíveis por meio do investimento em racionalização. No ponto de inflexão inferior, além das inovações sociais e das políticas governamentais, possibilitando que as novas tecnologias se implantem, outras mudanças sociais e políticas podem ser importantes ao fornecerem o estímulo necessário para apoiar a expansão em gestação (FREEMAN, 1984). 
A ligação entre ciência e riqueza não ocorre de forma direta. Por um lado, muitos dos avanços das ciências não tiveram aplicação no desenvolvimento econômico e, por outro, muitas das invenções tiveram sua explicação científica posteriormente. Contudo, a partir da fase B do segundo ciclo de Kondratieff (1873-1896), a ciência passou a ser aplicada ao desenvolvimento econômico, isto é, a ciência passou a ser um fator de produção. Tratouse da constituição da verdadeira revolução técnico-científica (BRAVERMAN, 1980). Esse processo teve sua gênese na Alemanha e tinha como objetivo romper com o atraso do desenvolvimento econômico.

Os esforços alemães, que posteriormente transferiram-se para os EUA, ocorreram, sobretudo, com a criação de escolas técnicas governamentais e dos laboratórios de pesquisa das grandes empresas. No Brasil, diversos foram os esforços governamentais para a criação de institutos de pesquisa, escolas técnicas e universidades ${ }^{5}$. Um dos exemplos marcantes no Brasil foi a constituição, em 1909, da Rede Federal de Educação Profissional, Científica e Tecnológica (RFEPCT). Nesse sentido, o trabalho de Jesué Gracialiano da Silva (2015, p. 11154) procura desvendar “[...] a expansão da rede federal de educação profissional, científica e tecnológica na região Sul do Brasil". Segundo o autor, de 2005 a 2014, foram construídas 418 novos campus em todas as regiões brasileiras. Já no Sul do Brasil, em 2005, a RFEPCT “[...] contava com 1 Universidade Tecnológica Federal - UTPFR com seus seis campus, com 4 CEFETs, 3 Unidades Descentralizadas, 9 Escolas Técnicas Vinculadas às Universidades - quase um terço do país - e 5 Escolas Agrotécnicas Federais, totalizando 28 unidades" (SILVA, 2015, p. 11156). "No final de 2014, a população atendida pelos 120 campus da RFEPCT da região Sul do Brasil foi da ordem de 50\% no Paraná, 52\% no Rio Grande do Sul e 56\% em Santa Catarina" (SILVA, 2015, p. 11158).

A constituição das instituições visava de forma inequívoca à necessidade da criação de um sistema nacional de inovação ${ }^{6}$. É nessa perspectiva que o trabalho de Sunamita I. Rodrigues e Ana Cristina de Almeida Fernandes (2015), intitulado "Sistema Territorial de Inovação: indícios da importância da dimensão espacial para processos inovativos”, procura dar uma dimensão territorial ao sistema nacional de inovação. As autoras destacam, com base em Metcalfe (1995), Albuquerque (1995) e Lundvall (1992), que o

\footnotetext{
5 Em termos formais Suzigan \& Albuquerque (2008) sugerem cinco “ondas de criação de instituições de ensino e pesquisa" no país.

6 O conceito de Sistema Nacional de Inovação (SNI) aparece precocemente nas ideias de F. List (1789-1846), ao defender a proteção as indústrias nascentes, como a necessidade de formulação de uma ampla política destinada a acelerar a industrialização e o crescimento econômico. A maioria dessas políticas era voltada para o aprendizado de novas tecnologias e de como aplicá-las. Reforçou a necessidade da responsabilidade governamental pela educação e treinamento e pela criação da infraestrutura de suporte ao desenvolvimento industrial (FREMAN; SOETE, 2005, p. 504). Freeman (1995) define o SNI como um conjunto de instituições, atores e mecanismos em um país que contribui para a criação, avanço e difusão das inovações tecnológicas. Destacam-se atores e mecanismos, os institutos de pesquisa, o sistema educacional, as firmas e seus laboratórios de pesquisa e desenvolvimento, as agências governamentais, a estrutura do sistema financeiro, as leis de propriedade intelectual e as universidades.
} 
Sistema Territorial de Inovação (STI) é uma construção, produto de uma ação planejada e consciente ou de um somatório de ações desarticuladas, que impulsiona o progresso tecnológico em economias capitalistas complexas, viabiliza o fluxo de informação entre produtores de ciência e tecnologia e os setores da economia e proporciona o arcabouço no qual governos formulam e implementam políticas para influenciar o processo de inovação. Constitui-se por elementos e relações que interagem na produção, difusão e uso de conhecimento novo e economicamente útil (RODRIGUES; FERNADES, 2015, p. 6320).

As políticas institucionais direcionadas para a construção de um Sistema Nacional de Inovação fez-se presente na criação de polos tecnológicos e incubadoras ${ }^{7}$. Em Florianópolis, o trabalho de Giselli Ventura de Jesus, denominado "A expansão urbana do Norte da Ilha de Santa Catarina", demonstra que a rodovia SC-401 transformou-se em um "corredor da inovação" devido ao elevado número de empresas de alta tecnologia. Segundo a autora, "Florianópolis é um dos três principais polos tecnológicos de Santa Catarina, assim como Blumenau e Joinville”. Juntos eles somam “[...] 50,3\% das empresas e 59,6\% dos empregos do setor" (JESUS, 2015, p. 6311).

\section{FINANCEIRIZAÇÃO DA ECONOMIA: ALGUNS ASPECTOS DA SUA REALIZAÇÃO NO BRASIL}

Do ponto de vista da dinâmica capitalista contemporânea, a financeirização da economia articula-se diretamente com temáticas desse GT. Necessário lembrar que a financeirização teve sua origem com Hilferding $(1985)^{8}$, que analisou pela primeira vez a formação do capital financeiro no início do século XX. Tratava-se do momento histórico da própria ascensão do capitalismo monopolista no decurso da Segunda Revolução Industrial, que permitiu a realização do processo de concentração e centralização do capital. Sua análise teve como idéias centrais a contradição entre a combinação da concentração e centralização do capital, a concorrência, a política protecionista, a exportação do capital e a dominação de espaços econômicos pelo capital financeiro (HILFERDING, 1985).

O autor partia da compreensão de como o capital industrial podia ser liberado da função empresarial pela formação de sociedades anônimas, e, com a venda de ações, cessava a necessidade de adiantar capital para o processo produtivo. No decurso do desenvolvimento do mercado de ações, ocorreu a expansão dos monopólios, acelerando tendências já colocadas por Marx (1988) sobre a centralização do capital, na qual a formação de cartéis expulsava os pequenos capitais de setores e atividades.

\footnotetext{
A consolidação dos polos tecnológicos no Brasil teve seu início em 1984 (KANITZ, 1998). As incubadoras podem ser caracterizadas como um condomínio empresarial que abriga fisicamente os empreendedores por um determinado período e facilita a superação de barreiras administrativas, técnicas e mercadológicas, beneficiando-se da infraestrutura e oportunidades estabelecidas (KANITZ, 2013).

8 A análise do capital financeiro e do imperialismo também foi realizada por Kautsky (1914), Bukharin (1984), Rosa Luxemburgo (1985), Schumpeter (1961), Hobson (1981), dentre outros.
} 
Os bancos tiveram papel fundamental nesse processo, pois foram os responsáveis pelo crescimento dos monopólios (HILFERDING, 1985). Em momento que a especulação e crédito para circulação decaiam, os bancos atraíram diversos fundos mediante pagamento de juros, transformando fundos em capitais industriais. Ao mesmo tempo, os bancos tiveram papel central na formação de cartéis, pois era mais difícil a falência de uma empresa com grande capital do que uma com pequeno capital. Nesse sentido, a discussão a respeito das três formas funcionais de capitais colocadas por Marx (capital industrial, capital bancário e o capital comercial) passou a ter relativa autonomização.

Uma porção cada vez maior do capital da indústria não pertence aos industriais que o aplicam. Dispõem do capital somente mediante o banco, que perante eles representa o proprietário. Por outro lado, o banco deve imobilizar uma parte cada vez maior de seus capitais. Tornase assim, em proporções cada vez maiores, um capitalista industrial. Chamo de capital financeiro o capital bancário, portanto o capital em forma de dinheiro que, desse modo, é na realidade transformado em capital industrial. Mantém sempre a forma de dinheiro ante os proprietários, é aplicado por eles em forma de capital monetário - de capital rendoso - e sempre pode ser retirado por eles em forma de dinheiro. Mas, na verdade, a maior parte do capital investido dessa forma nos bancos é transformado em capital industrial, produtivo (meios de produção e força de trabalho) e imobilizado nos processos de produção. Uma parte cada vez maior do capital empregado na indústria é capital financeiro, capital a disposição dos bancos e pelos industriais (HILFERDING, 1985, p. 219).

Ao mesmo tempo em que ocorria a concentração e centralização do capital no contexto do imperialismo, alterava a relação entre a burguesia e o Estado. Na análise de Hilferding (1985), o Estado passava a proteger os cartéis, a produção nacional, mediante estabelecimento de tarifas protecionistas. Estas por sua vez, ampliavam ainda mais os lucros de empresas que se tornavam monopolistas. E se o protecionismo não fosse suficiente para as empresas no mercado interno, exportavam-se capitais na forma de envio de tais divisas ao exterior, para gerar mais-valia (HILFERDING, 1985, p. 295). Ao mesmo tempo, para a expansão do capital financeiro era necessário um "[...] Estado forte que faça valer seus interesses financeiros no exterior, que entregue seu poder político para extorquir dos Estados menores vantajosos contratos de fornecimento e tratados comerciais" (HILFERDING, 1985, p. 314).

Ainda no início do século XX, Lênin (2012) ao analisar o imperialismo, entendia-o como "[...] a fase monopolista do capitalismo" (LENIN, 2012, p. 124). O autor apontava em sua definição, cinco características fundamentais:

1) a concentração da produção e do capital [...] criou os monopólios, os quais desempenham um papel decisivo na vida econômica; 2) a fusão do capital bancário com o capital industrial e a criação, baseada nesse 'capital financeiro' da oligarquia financeira; 3) a exportação de capitais, diferentemente da exportação de mercadorias, adquire uma importância particularmente grande; 4) a formação de associações internacionais monopolistas de capitalistas, que partilham o mundo entre si, e 5) o termo da partilha territorial do mundo entre as potências capitalistas mais importantes. 
Em linhas gerais, as análises de Lênin (2012) não eram divergentes daquelas efetuadas por Hilferding (1985). Após intensas discussões sobre o capitalismo financeiro e imperialismo no início do século XX, o tema ficou relegado a segundo plano após a Primeira Guerra Mundial. Isso se deveu, em grande parte, pelo fato de surgirem novas preocupações teóricas e práticas que se tornaram centrais no debate sobre o capitalismo: até os anos 1950, o planejamento e o processo de construção do socialismo na União Soviética e, após os anos 1950, o desenvolvimento dos países do chamado Terceiro Mundo. As análises sobre o avanço do capital financeiro ou da financeirização, ganhou mais atenção a partir dos anos de 1970.

Na segunda década do século XXI ${ }^{10}$, as temáticas discutidas por Hiferding (1985) e anteriormente colocadas, continuam válidas, mas, ganha destaque a questão do capital fictício mediante sua expansão, bem como, outros elementos utilizados para a continuidade da valorização do capital, como fundos de pensão, fundos de investimentos, seguradoras, etc. que procuram diversas fontes de acumulação na esfera produtiva e especulativa (CAMPOS; SABADINI, 2014). Não mais apenas os bancos, outros agentes sociais passaram a atuar na expansão financeira, como os investidores institucionais, por exemplo.

O capital fictício é a multiplicação ilusória da riqueza com base no capital portador de juros (MARX, 1985). De acordo com Germer (1994, p. 194), o que é “[...] significativo no conceito de capital fictício é que, ao ser emprestado, o dinheiro concentrado nos bancos se duplica em dinheiro e em títulos que representam direitos sobre dinheiro". Por isso, o capital fictício diferencia-se do capital produtivo:

[...] como também do capital monetário, que não é capital real, mas é forma monetária do capital ou é simplesmente dinheiro, equivalente geral da riqueza, e, nesse sentido, não é fictício. Um título de crédito não é capital em nenhuma dessas formas, é apenas direito a capital ou a dinheiro (GERMER, 1994, p. 195).

Esses títulos, como exemplares do capital fictício, apresentam movimento próprio, distinto do capital real e monetário, cujo comportamento é flutuante em razão inversa das taxas de juros, ilustrando o que Marx denominou de capitalização (GERMER, 1994). Assim, no capital fictício:

\footnotetext{
Esse momento foi marcante para o capitalismo diante da crise recessiva mundial, que adentrava na fase b do quarto ciclo longo de Kondratieff. Teve como marco a crise do petróleo e, conforme exposto anteriormente, a fase recessiva é marcada pela busca de inovações em processos e produtos, bem como caminhos para reprodução ampliada do capital.

10 Identificam-se várias vertentes em direção à análise da expansão da financeirização: uma delas deriva de uma crítica marxista, que considera a financeirização como um excrescência do sistema capitalista por não estar centrada na produção propriamente dita; que acentua seu caráter parasitário; outra vai em direção à compreensão da financeirização como etapa do desenvolvimento do capitalismo, isto é, da continuidade do processo de produção e reprodução das relações sociais capitalistas; bem como não acatam a idéia do distanciamento entre a esfera financeira e produtiva; outra vertente aceita a ideia de que o capital fictício tem proeminência sobre outras formas de capital, distanciando-se muito da esfera produtiva. Embora sejam algumas aqui apontadas, no interior de cada uma delas, há interpretações muito heterogêneas, mesmo que marcadas por uma perspectiva marxista (CAMPOS; SABADINI, 2014).
} 
[...] o valor do capital é deduzido do valor do rendimento, dada a taxa de juros. Isto é, o valor do capital consiste na capitalização dos rendimentos conhecidos ou esperados (MARX, 1985, p. 11). Transformar essa regra prática em relação causal teórica significa aceitar o fenômeno irracional em que o resultado gera a sua causa, ou o ente gera seu criador. Em suma, o capital, nesse caso, é apenas o valor que o capitalista está disposto a pagar, dada a taxa de juros, pelo direito a determinado rendimento futuro, conhecido ou estimado (GERMER, 1994, p. 196).

Se se destaca aqui o capital fictício, é para chamar a atenção de um dos elementos que mais tem sido reiterado por vários pesquisadores da conhecida financeirização da economia. Chesnais (1996) é um dos autores que passou a centrar ênfase no capital fictício em detrimento do capital a juros em direção ao que denominou de regime de acumulação predominantemente financeirizado. Na concepção do autor, “[...] o movimento do capital monetário [capital-dinheiro], que se ergue como força plenamente autônoma diante do capital industrial, deixando a este uma única alternativa: ou acentuar o movimento no sentido de profunda interpenetração com o capital monetário, ou submeter-se às exigências deste" (CHESNAIS, 1996: 52-53).

Muitas críticas foram realizadas a essa compreensão, e de modo geral há muitas controvérsias sobre o tema. No entanto, admite-se aqui as idéias de Germer (1994, p. 199-200), de que:

O capital fictício aparece como o coroamento fantástico de todo o edifício, um castelo de papel de colorido espalhafatoso, que oculta o processo de produção em que o capital e o trabalho se enfrentam e, de certa maneira, tumultua o cenário teórico e inverte os dados da realidade: de fato, a riqueza ilusória do papel pintado aparece a todos como a mais sólida realidade, enquanto o processo granítico de trabalho, através do qual o ser humano deve continuar subjugando a natureza, parece uma fantasia ultrapassada.

A partir desses apontamentos, pode-se articular a discussão realizada por Corrêa (2015) a respeito das fusões e aquisições de empresas brasileiras, em direção à desnacionalização e desindustrialização a partir dos anos de 1990. Essas fusões e aquisições trazem em seu bojo a elevação da desnacionalização da indústria brasileira, das telecomunicações, sistema bancário, dentre outros, bem como demonstram os efeitos dos investimentos externos diretos (IED).

Esses investimentos externos correlacionam-se com as discussões anteriores sobre a financeirização, no sentido de exportar capitais em direção à obtenção de mais-valia, posto tratar-se de operações de investimentos em produção, tratando-se, portanto, de capital produtivo. Ao mesmo tempo, são investimentos externos diretos para controlar bancos, reproduzirem a concentração e centralização do capital e dar continuidade na expansão do capital fictício. Esses processos realizam-se com forte apoio do Estado brasileiro em criar caminhos institucionais para permitir a entrada dos mesmos, sem políticas macroeconômicas a fomentar a economia nacional. 
Medeiros (2015, p. 6223) discute a financeirização na agricultura brasileira e o papel do Estado, com enfoque para a dinâmica geral do capital financeiro imposta à agricultura mundial, principalmente no que tange à:

[...] contínua expansão dos grandes grupos internacionais de comércio e produção de insumos e de produtos agrícolas, de financiamento e de biotecnologia, alavancados pela ampliação da circulação de títulos financeiros agropecuários e pelas bolsas de mercadorias (MEDEIROS, 2015, p. 6224).

Em outros termos, Medeiros (2015) deixa claro alguns dos caminhos por meio dos quais a financeirização atingiu a agropecuária e agroindústrias brasileiras, que passou a ser alvo de investimentos na produção de alimentos, sementes e fertilizantes; ocorreu ainda a incorporação de que, segundo Medeiros (2015), não se articula com a incapacidade tecnológica ou competitiva, mas sim, com a ação deliberada de investimentos externos diretos, fortalecendo os monopólios internacionais.

O Estado brasileiro, porém, reagiu a partir do governo Lula, assumindo parcela da política monopolista e, por intermédio do Banco Nacional de Desenvolvimento Econômico e Social - BNDES, possibilitou investimentos e “[...] reestruturação interna, quanto para aquisições de grupos estrangeiros, numa lógica inversa a da década de 1990. Internacionalização ao invés de desnacionalização" (MEDEIROS, 2015, p. 6228). Nesse caminho, o BNDES passou a ser um agente regular da política industrial de Estado e, ao mesmo tempo, começou a fornecer apoio a políticas anticíclicas em etapas recessivas. Mais ainda, porque passou a ampliar sua participação acionária em grandes grupos do setor agroindustrial, tornando essa atividade a mais rentável do BNDES (MEDEIROS, 2015).

Se, por um lado, a financeirização da agropecuária e agroindústria brasileira possibilitou a formação de grupos econômicos no sentido da monopolização e internacionalização, por outro, a financeirização ainda expande seu controle na pesquisa tecnológica de insumos, em que as inovações tecnológicas continuam sendo centrais.

A financeirização assume uma das faces mais evidentes do capital fictício com o trabalho de Schatz (2015), sobre a transformação da prática esportiva, o futebol, em mercadoria a partir dos anos de 1970. Mediante discursos e práticas diversas, o futebol e a complexa rede de elementos a ele vinculada - financiamentos de campeonatos mediante propagandas de corporações internacionais, como Coca-Cola, Adidas; consumo de produtos de clubes; cotas de televisão; etc. - passaram a ser alvo de ação de grupos nacionais e internacionais, a negociarem e investirem no espetáculo dos gramados. Tanto assim que “[...] a área dos esportes busca o dinamismo econômico e o controle do mercado através das empresas promotoras do espetáculo esportivo que são capazes de transformar práticas lúdicas em artigos de alta lucratividade" (SCHATZ, 2015, p. 6294). 


\section{IMPLICAÇÕES E REAÇÕES EM FORMAÇÕES SOCIAIS PERIFÉRICAS}

No último quartel do século XX, a hegemonia de políticas de desregulamentação das matrizes essenciais do fordismo-keynesianismo, encontrou terreno fértil com o desmonte da União das Repúblicas Socialistas Soviéticas (URSS), a queda do muro de Berlim e com a crise instalada não apenas do ponto de vista econômico e social, mas também entre parte da intelectualidade, órfã daquele modelo de socialismo. Esta intelectualidade adotou direta ou indiretamente o discurso pouco reflexivo que advoga a vitória inequívoca do capitalismo e da supremacia estadunidense sobre o sistema mundial. Nessa perspectiva, resultaram, por exemplo, interpretações baseadas no "choque de civilizações" (HUNTINGTON, 1997) ou em odes ao processo de constituição de uma inexorável ordem global ditada pela supremacia do mercado, eivadas de equívocos propositais ou simplesmente conduzidas por discursos motivacionais deslocados da materialidade das contradições estruturais das relações capital-trabalho e capital-capital, que, nas múltiplas escalas, constituíram o que Krugman (1997) chamou de "globobagens".

Nos primeiros anos do século XXI, os governos eleitos nas formações sociais periféricas, implementaram políticas de capitulação das embrionárias iniciativas para a construção de projetos que objetivavam a elevação das forças produtivas, articulando capitais de diferentes origens com a coordenação estatal para dirimir as profundas desigualdades sociais e territoriais. Na essência, a postura revelou a perversidade do que foi apregoado e imposto como a nova ordem: a hegemonia do capital financeiro.

A hegemonia imposta na conjunção de um ideário repetido exaustivamente em ambientes acadêmicos e midiáticos, capilarizada do centro do sistema para setores estratégicos das sociedades da periferia do sistema, para solapar os marcos regulatórios que permitiam projetos e ações com marcas da autonomia para o desenvolvimento e o crescimento econômicos com políticas redistributivas de renda. Entre os resultados está o aprofundamento das desigualdades de distribuição de renda e de concentração da riqueza entre as classes e os países, e a reafirmação da pretensa incapacidade das sociedades periféricas em produzir políticas e ações criativas que geram proposições e, movimentos, e questionam a hierarquia do sistema mundial.

Na lógica contraditória do desenvolvimento do capitalismo, emergiram forças políticas em diferentes formações sociais que, portadoras de discursos e projetos nacionais, apregoavam as múltiplas possibilidades das relações internacionais.

Esse é um dos sentidos e relevância dos trabalhos apresentados por Elisa Gomes Prestes (Brasil e China: suas aproximações e distanciamentos) e Lucas Santos Ferreira (Geografia 
da recuperação econômica: Argentina- 2003-2015). Do ponto de vista de parte da avaliação na Geografia hegemonicamente produzida no Brasil, ambos colaboram para produzir análises diferenciadas que sustentam o significado da escala nacional conectada com os processos do sistema mundial. Nesse sentido, estão em posição que se afasta da hegemonia dos trabalhos de mestrado e doutorado realizados nos programas nacionais assentados nas escalas locais e regionais (SUERTEGARAY, 2005; 2007). O registro preciso dessa questão foi realizado por Mamigonian (2006, p. 8) chamando a atenção de que: "Milton Santos insistia na necessidade de a geografia brasileira estudar outros países, aumentando sua área de atuação intelectual, superando os limites impostos pela geografia dos países dominantes (EUA e Europa)”.

Assim, o trabalho de Prestes (2015), faz uma relação acerca da atual conjuntura política e econômica mundial, considerando o novo desenvolvimento econômico-social do Brasil a partir do século XXI, e a ascensão da República Popular da China como superpotência econômica. Nessa perspectiva a pesquisa de Prestes (2015), reflete sobre os desafios e as oportunidades para a China e o Brasil na geopolítica Mundial. A autora está em consonância com o texto de Ferreira (2015) que, com base na análise da formação social argentina e de suas transformações recentes, descortina o processo de recuperação econômica da Argentina no período de 2003 a 2015, bem como alguns de seus impactos regionais com base em variáveis geoeconômicas atuantes na superação do fracassado plano de conversibilidade do período neoliberal dos governos de Carlos Menem, entre 1989 e 1999, sobretudo com a influência das políticas neoliberal do ministro Domingo Felipe Cavallo.

Um dos caminhos para garantir a viabilidade dos projetos nacionais e a constituição de aproximações entre países e, quiçá, de blocos de países, é a aceleração das trocas comerciais que, ao exigir negociações, desenhos de consensos mínimos e pactuações, ativam as melhores inteligências para inovar na busca de condições materiais e não materiais para a concretização dos deslocamentos e das trocas.

O tema do comércio e das comunicações é um dos pilares clássicos do processo de formação e institucionalização da Geografia. Friedrich Ratzel (1844-1904), em sua perspectiva evolucionista é incisivo na busca de determinações geográficas, ao explicar que populações que, ao longo do tempo, não viveram exclusivamente do solo de seus territórios tem “[...] naturalmente necesidad de entrar em relación com otras tierras" (RATZEL, 1982, p. 201).

De outra parte e indispensável para a formação da Geografia brasileira é a preocupação que está fartamente registrada em Paul Vidal de La Blache (1845-1918). Na sua obra 
original de 1921, "Princípios de Geografia Humana- a marcha da humanidade" (1954), e, particularmente, no capítulo "a evolução das civilizações", o autor ressalta os "contatos por invasão e oposição dos modos de vida" e "os contatos pelo desenvolvimento do comércio marítimo (p. 279-288). Porém, é na terceira parte do livro intitulada "a circulação" que o autor registra a importância dos meios de transporte, das estradas, das ferrovias e do mar. Em uma de suas sínteses coloca que

\section{[...] todos estes sistemas de comunicações forma-se uma rede que podemos qualificar de mundial [...] abarca, se não a totalidade do globo, pelo menos uma extensão assaz [...] é resultado de combinações múltiplas, realizadas, em meios diferentes, pelo carril, pela navegação marítima ou pela interior (VIDAL DE LA BLACHE, 1954, p. 344).}

$\mathrm{Na}$ fecunda produção dos geógrafos com preocupações centrais nas dinâmicas econômicas em sua totalidade com eixo na circulação, esta o sumário do significado das transformações técnicas para a aceleração das trocas. É, pois, nesse sentido, que Otembra (1959), associa o papel na circulação no direcionamento do dinamismo econômico mundial.

Uma parte dessa tradição está no texto de Machado (2015), que retoma a relevância estratégica do transporte marítimo para as mais diversas civilizações, por meio do mercantilismo e do capitalismo manufatureiro, que engendraram as relações comerciais centro-periferia e mundializaram a economia. Assim, os portos e a navegação adquirem um novo status, o de papel central nas relações comerciais, passando por verdadeiras revoluções. No novo cenário, consideram a teoria dos ciclos longos (Kondratieff), na qual as ondas de inovações, implementadas na fase expansiva do ciclo, propiciaram grandes alterações no cenário econômico e político mundial.

Coerentes com a perspectiva do GT, os textos de Lacerda (2015) e de Zeferino (2015), abordam a dinâmica setorial dos gargalos nas infra-estruturas em país de dimensões continentais como o Brasil. O primeiro, ao apresentar a potência do setor agroalimentar instalado no Brasil meridional, aponta a agressividade de suas empresas no mercado internacional. Zeferino (2015) desenha mais um elemento que seria um acréscimo nas vantagens competitivas das agroindústrias alimentares sulinas: a utilização das vias navegáveis do interior do país.

Indicada a articulação entre os dois textos, é possível assinalar suas especificidades. Lacerda (2015), ao apresentar os principais produtos presentes na pauta exportadora das agroindústrias do Sul do Brasil, ressalta a sua participação no processamento de bens intermediários e bens finais, retratando a diferença entre commodities brutas e processadas. Assim, o autor se insere no debate quanto às questões de reprimarização e desindustrialização da economia brasileira. Em Zeferino (2015), há sinais do refinamento 
da discussão da integração nacional com a retomada da navegação por cabotagem. Após o desmonte planejado na escassa malha ferroviária e da estrutura material e de pessoal capacitado, a autora defende a necessidade de se revitalizar e modernizar o setor portuário para o crescimento econômico do Brasil.

\section{INOVAÇÕES E PRODUÇÃO NO BRASIL}

As inovações são uma preocupação presente quando se foca não apenas nas movimentações de capitais em sua feição financeira ou comercial, mas também em seus aspectos produtivos. A produção propriamente dita é fundamental no processo de acumulação capitalista. Dessa forma, a análise das inovações (processos e produtos) e das estratégias empresariais torna-se central para entender os movimentos do capital produtivo.

A constituição de um mercado global é característica do capitalismo desenvolvido, como já apontado por Bukharin (1985) e Lenin (2012). Não há muitas novidades no que a literatura dos anos 1990 apresentou como a "globalização" do final do século XX a não ser a volta de políticas econômicas sobre territórios que já vinham sendo adotadas desde o final do século XIX sob o título de imperialismo. Muito se escreveu sobre a "globalização" dando a ela um caráter de justificativa do abandono das políticas de desenvolvimento nacional que vinham sendo adotadas por países periféricos no pós-Segunda Guerra Mundial. A idéia de um mundo sem fronteiras e do fim do Estado Nacional mostrou-se apenas uma ideologia para o consumo da periferia, nunca adotada de fato pelos países centrais. A idéia de "globalização" se transformou em uma grande ideologia contrária às políticas de desenvolvimento nacional autônomo, aprofundando relações de dependência e submissão aos países centrais.

O entendimento das políticas de desenvolvimento nacional é fundamental para que se possa pensar na produção industrial e agrícola. Assim, entender a inserção do Brasil na Divisão Internacional do Trabalho (DIT) em seu desenvolvimento histórico e mudanças de centros dinâmicos é central para que se possa analisar o processo de acumulação de capital interno ao país. Nesse sentido, o papel da tecnologia e inovação é essencial. Vale lembrar a idéia de Domenico Losurdo (2011) que afirma que "liquidar o monopólio ocidental da tecnologia é também luta revolucionária ${ }^{11 "}$, ou seja, o domínio tecnológico está diretamente ligado à forma como vamos nos inserir na DIT.

A preocupação com o caráter dessa inserção foi algo presente nos debates do GT, visto que, nos trabalhos apresentados, a relação local-global-nacional sempre esteve

${ }_{11}$ Entrevista concedida pelo autor à revista Chinese Social Sciences Today, cuja tradução está disponível em http://resistir.info/ losurdo/losurdo_15dez11.html. 
presente. Os trabalhos que discutiram a produção propriamente dita, ou seja, os ramos industriais e agrícolas, demonstrando uma perspectiva analítica que dá destaque para dois pontos centrais: (a) as estratégias empresariais ligadas à acumulação, na qual se incluem as inovações em processos ou produtos; e (b) as ações estatais, seja na forma de políticas públicas específicas (locais ou nacionais), seja nas estratégias de competitividade global, levando em conta fatores como câmbio, infra-estruturas, financiamento e política de crédito.

O agronegócio foi debatido do ponto de vista de sua inserção mais ampla na economia nacional, não caindo na falsa dicotomia entre agronegócio e agricultura familiar, debate um tanto estéril quando se tem como preocupação o processo geral da acumulação de capital e as estratégias nacionais de inserção na Divisão Internacional do Trabalho ${ }^{12}$. Entendese que tanto a chamada agricultura familiar quanto a chamada agricultura empresarial (ou agronegócio de escala) são vertentes de uma agricultura comercial capitalista, cuja finalidade principal é a produção de lucro. Analisar o agronegócio hoje traz à tona a necessidade de entender a divisão social do trabalho ${ }^{13}$ como ponto central e, dessa forma, as relações entre o urbano e o rural. Assim, deve-se lembrar que a criação dos mercados para produtos alimentares se dá pelo processo de urbanização e que é na cidade que se tem o pólo dinâmico da acumulação do capital produzido no campo. Também é importante ressaltar que cada vez mais os trabalhadores rurais vivem nas cidades e, igualmente, é nas cidades que se produzem as inovações e equipamentos que serão utilizados na agricultura.

Os trabalhos de Cunha (2015) e Camilo (2015) trataram dos agronegócios da soja e do leite, respectivamente. A preocupação com as infra-estruturas e com a logística esteve presente em ambos os trabalhos, apesar da diferença regional das áreas de estudo, o primeiro analisando o Maranhão e o segundo o Sul do Brasil. Isso mostrou que algumas questões são de escopo nacional e global e não apenas local. Os aspectos locais, ligados a formações sociais diferentes, também estão presentes nos trabalhos.

Cunha (2015) mostrou que as atividades pós-porteira são os principais pontos de estrangulamento na cadeia de soja no Maranhão. As estradas em más condições e a falta de um número maior de ferrovias criam custos adicionais para o escoamento da produção, além da dependência das tradings, que acabam atuando como oligopólios e oligopsônios. Apesar desses problemas, o autor mostra que, pela proximidade do porto de Itaqui-MA, o custo de escoamento ainda é menor do que o apresentado para a produção do estado de Mato Grosso.

${ }_{12}$ Há ampla literatura sobre o tema e indicam-se aqui algumas obras que servem de base para fundamentar nossa posição teórica: Gonçalves (2004), Germer (2002), Soares (1999) e Navarro (2010).

13 O papel da divisão social do trabalho na formação dos mercados é tema debatido por Lenin (1985), ao analisar o desenvolvimento do capitalismo na Rússia. Tal temática, do ponto de vista nacional, também foi abordada em vários textos de Ignácio Rangel (2000). 
Camilo (2015) deu ênfase às estratégias empresariais no setor lácteo, em específico aos processos de fusões e aquisições que ocorreram no setor nas últimas décadas, com importante papel do capital financeiro, gerando empresas gigantes na captação e industrialização do leite. Esse processo, segundo o autor, levou a uma grande desnacionalização do setor. Também deu destaque ao papel do Estado como fomentador da modernização da atividade por meio de adoção de inovações e políticas de financiamento e aquisição da produção.

A produção leiteira também foi estudada por Vasconcelos Junior (2015) que, além de abordar a atuação mais geral das políticas federais, apresentou as características locais e as especificidades da bacia leiteira do semi-árido alagoano. Tomando como base a ideia de combinações geográficas de Cholley, fez um resgate histórico do desenvolvimento da atividade e da incorporação tecnológica no melhoramento genético e alimentar do rebanho, da incorporação de máquinas e da industrialização do leite impulsionadas pela urbanização.

As especificidades locais e a adoção de políticas nacionais ficam bem marcantes ao se comparar os trabalhos de Camilo (2015) e Vasconcelos Júnior (2015), a característica de pequenos produtores muito pouco capitalizados do semi-árido alagoano contrasta com o produtor altamente tecnificado do Sul do Brasil, região que se tem tornado uma das principais bacias leiteiras nacionais.

Ao se analisar a dinâmica do agronegócio familiar do Sul do Brasil, dois pontos mostraram-se como fundamentais para o seu entendimento (a) o papel das cooperativas; e (b) o papel do crédito para o pequeno proprietário adotado nas duas últimas décadas ${ }^{14}$. Farias (2015) e Padilha (2015) dedicaram seus trabalhos a apresentar as principais estratégias das cooperativas do Sul do Brasil. O Sul do Brasil é a região em que mais se desenvolveu o cooperativismo, tendo algumas dessas cooperativas se tornado empresas gigantescas com poder de concorrência com as grandes tradings mundiais.

Farias (2015) mostrou que a adoção de diferentes estratégias empresarias foi fundamental para a consolidação e diferenciação das cooperativas da região Sul. As políticas estaduais foram fundamentais no fortalecimento das cooperativas paranaenses, que se tornaram as mais competitivas do país; já em Santa Catarina, foi a concorrência com os grandes grupos agroindustriais privados que possibilitou a consolidação das cooperativas. Farias (2015) destacou que as cooperativas do Sul desempenharam um papel estratégico na difusão tecnológica e na organização produtiva da agricultura do Sul brasileiro, a partir do financiamento da produção, assistência técnica e acesso à tecnologia. A agricultura é um

${ }_{14}$ O Programa Nacional de Fortalecimento da Agricultura Familiar (Pronaf) foi criado em 1996 durante o governo de Fernando Henrique Cardoso, mas foi no governo de Luiz Inácio Lula da Silva que se aumentaram substancialmente os recursos para o programa, tornando-se a principal política de financiamento da chamada agricultura familiar. 
setor muito dependente de crédito, visto que, em grande parte das culturas, é necessário esperar um grande período para que o produto esteja pronto para a venda. Dessa forma, a existência de políticas de crédito e financiamento agropecuário é fundamental para referida atividade. Foi nesse sentido que Padilha (2015) mostrou as particularidades da política de crédito para as cooperativas do Sul do Brasil. A existência de crédito, segundo o autor, foi a responsável pelos investimentos das cooperativas em infraestrutura produtiva, comercial e na composição do capital de giro. As políticas oficiais de crédito para as cooperativas possibilitaram o excelente desempenho delas nas últimas décadas, impulsionadas pelas oportunidades geradas pela alta do preço das commodities agrícolas, do crescimento do mercado interno e da melhoria da infra-estrutura e logística.

Os trabalhos apresentados sobre a dinâmica da agricultura brasileira tiveram a preocupação de mostrar as especificidades da formação social, a adoção das estratégias empresariais de inovação e difusão, e o papel das políticas públicas como indutoras do desenvolvimento do setor, não apenas no agronegócio de escala como também nos agronegócios familiares. Em geral, as abordagens não ficaram restritas à "porteira pra dentro", mas buscaram um entendimento da inserção com políticas mais amplas do desenvolvimento nacional. Assim, a relação entre o urbano e o rural aparece de forma articulada na lógica da acumulação capitalista.

Do ponto de vista da indústria de transformação, uma das preocupações centrais que se tem é relativa às estratégias adotadas para a competição internacional. Dessa forma, retoma-se a preocupação com a forma como vamos nos inserir na DIT e as estratégias setoriais utilizadas para sobreviver em uma concorrência predatória com outros países após a adoção das políticas neoliberais a partir dos anos 1990. Nesse sentido, Rosa (2015) mostrou as estratégias espaciais adotadas pela indústria calçadista brasileira que sofre uma dupla concorrência, tanto no setor de calçados com baixo valor agregado, concorrendo diretamente com a China, quanto no setor de calçados com maior valor, cuja concorrência se dá com Portugal, Espanha e Itália. As estratégias empresariais estão não apenas na inovação, mas também na localização produtiva, buscando áreas com mão de obra mais barata (Nordeste brasileiro) e a especialização produtiva nos calçados de maior valor agregado, atentando-se para as preferências dos consumidores e buscando uma intensa diferenciação em produto.

Rosa (2015) igualmente expõe alguns aspectos gerais da industrialização ligados à reação da indústria brasileira à dinâmica dos ciclos longos. Dessa forma, esclarece que as estratégias ligadas à acumulação não são apenas utilizadas por empresas, mas também pelos Estados que adotam modelos de desenvolvimento baseado na transferência de parte do 
seu parque industrial para a periferia do sistema. Segundo o autor, tal estratégia, além de possibilitar a reestruturação produtiva no centro ao levar as indústrias tecnologicamente maduras e intensivas em trabalho para os países periféricos, pode

a) prolongar a vida útil do aparato produtivo tecnologicamente obsoleto e que foram direcionados aos novos produtores periféricos estendendo, portanto, seus lucros sob a forma de repasse de equipamentos a países em vias de industrialização, e b) importar produtos manufaturados, sobretudo os de consumo simples como calçados, têxteis, etc.; a preços mais convidativos produzidos na periferia e que serviram para manter estáveis o poder de compra da massa trabalhadora sem elevação real dos salários, notadamente, fazendo arrefecer a pressão exercida pelo capital variável sobre as taxas de lucro (ROSA, 2015, p. 6283).

Com a abertura comercial e a inserção submissa na chamada "globalização", a preocupação com o setor industrial tomou vários rumos, tanto o debate sobre a desindustrialização - reprimarização, quanto o debate sobre a desconcentração industrial e o desenvolvimento local. $\mathrm{Na}$ falta de uma política industrial nacional mais robusta, o foco no desenvolvimento local como paliativo econômico e social tornou-se um tema bastante discutido.

Nesse sentido, o trabalho de Santos e Correa (2015) é esclarecedor. Partindo da análise das políticas de Arranjos Produtivos Locais (APLs), adotados em Alagoas, os autores mostraram que houve grande esforço de instituições públicas e privadas na elaboração dos Arranjos, objetivando ganhos de produtividade das atividades tradicionais a partir da adoção de inovações e do apoio institucional. Tais políticas possibilitaram o aumento do emprego e da renda de micros e pequenos empresários, mas, em geral, não tocaram nos problemas fundamentais da formação social alagoana, o atraso e a questão da terra. Dessa forma, os autores concluem que ainda há no estado uma grande dependência das transferências de renda obtidas pelos programas federais (como o Bolsa Família, por exemplo) e que a adoção dos APLs acaba por tirar o foco de políticas baseadas em grandes projetos estruturantes.

As implicações dessas discussões também se realizam na cidade por diversos caminhos. Um deles se vincula à expansão de centralidades intra-urbanas, comandadas por incorporadoras e construtoras, sejam elas de capital aberto ou fechado. O trabalho de Wenning (2015) a respeito da produção de outras centralidades intra-urbanas em Blumenau - SC, principal cidade de uma região metropolitana, demonstra a articulação entre empreendimentos imobiliários e expansão do consumo por meio dos shopping centers. No entanto, no caso em foco, há fortes vínculos entre a localização desses shoppings com a questão natural da cidade (localizada no vale do rio Itajaí-Açu e afluentes), a densa rede de cidades em direção à ampliação da aglomeração urbana e a rede de transporte rodoviário. 
Por isso, apontava a autora que os dois mais recentes shopping centers localizam-se na porção norte, área menos suscetível à enchente e, ao mesmo tempo, de fácil localização para as cidades de sua aglomeração urbana.

Florianópolis igualmente passa por expansão de empreendimentos imobiliários voltados para atividades comerciais, principalmente para empresas tecnologias na porção norte da Ilha. Isso demonstra formas distintas da expansão de empreendimentos imobiliários a atenderem ou criarem demandas do polo tecnológico da cidade. Esse segmento tecnológico vem se colocando como um dos mais importantes na geração do PIB do município, representando cerca de 20\% em 2007 (JESUS, 2015).

Inovações também se realizam diretamente com a produção da cidade e do urbano. Em outros termos, produzir shopping centers, edifícios verticais, etc., também passou a apresentar alterações. Incorporadoras e construtoras nacionais adentraram na financeirização mediante abertura de seus capitais na Bolsa de Valores como forma de captação de recursos para expandir suas atividades; parcela das ações está sob o controle de fundos previdenciários nacionais, de fundos do tipo Equity, etc., manifestando tendência da financeirização global. Por outro lado, outras empresas do setor da construção civil acabaram por perder o controle do capital para o capital internacional. Alterações igualmente se realizam na forma de controle e administração de shoppings, com avanço das denominadas administradoras em quase todo o país.

\section{CONSIDERAÇÕES FINAIS}

A crise econômica e financeira do sistema capitalista iniciada em 1973 forçou diferentes formações sócio-espaciais nacionais e regionais a adotarem medidas políticas e institucionais assentadas nos mais variados ideários. No Brasil, tais medidas, combinadas com as estratégias dos agentes sociais, resultaram em formas diferenciadas de apropriação do espaço urbano e rural, bem como promoveram um intenso processo de reestruturação técnica e econômica nas estruturas produtivas.

Essas reestruturações, apoiadas em grande medida na lógica da financeirização, fizeram a partir de inovações em processo, produto e organizacionais, que se manifestassem na expansão da rede federal de educação profissional, cientifica e tecnológica na região Sul do Brasil, na criação de um sistema territorial de inovações, na concentração da produção, na financeirização da agricultura brasileira, na reprodução do capital fictício, na transformação da prática esportiva em mercadoria, na aproximação de relações comerciais e econômicas do 
Brasil com a China, na constituição de blocos econômicos, na emersão de novas potencias mundiais (China), na busca incessante para o rompimento dos estrangulamentos em infraestrutura, no aumento da navegação de cabotagem, na ampliação dos agronegócios de soja e leite, no crescimento dos investimentos das cooperativas, na expansão de diferentes segmentos industriais e na disseminação de arranjos produtivos.

Tais transformações tiveram impactos no espaço urbano com a construção e desconstrução de centralidades intra-urbanas, a partir da atuação de construtoras regionais, evidenciando percursos distintos de desenvolvimento das formações sócio-espaciais regionais brasileiras.

Para ratificar a proficuidade da perspectiva central do GT, apresenta-se um leque de questões que podem servir para o refinamento e a eficácia de pesquisas futuras:

a. É possível manter a essência da radicalidade teórica que amálgama a compreensão do modo de produção com a sua viabilização nas formações sócio-espaciais, evitando os excessos de determinadas determinações?

b. Quais os caminhos para apreender as acelerações das dinâmicas contraditórias das relações entre as forças produtivas e as relações sociais que permitem entender as múltiplas escalas?

c. A hegemonia do capital financeiro que penetra em todos os setores e tendencialmente se impõem nos recônditos da vida, é suficiente para entender as acelerações dos processos, a destruição e a reconstrução nos campos e nas cidades e nos distintos setores econômicos?

d. Como a compreensão das lógicas dos progressos técnicos pode captar as ligações e os afastamentos entre o campo e cidade?

Por fim, o aprofundamento da perspectiva teórica que inspirou o GT, materializadas nos trabalhos apresentados pode ser um dos componentes essenciais para apontar os limites e as possibilidades para a superação dos impasses da hegemonia da financeirização e para a racionalidade da perversa da desigualdade que se naturaliza no modo produção capitalista. Tornando-se, portanto, fundamentais para a produção científica.. 


\section{REFERÊNCIAS}

1. BRANDÃO, C. Território \& desenvolvimento. Campinas: Unicamp, 2012.

2. BRAVERMANN, H. Trabalho e capital monopolista: a degradação do trabalho no século XX. Rio de Janeiro: Zahar editores, 1980.

3. BUKHARIN, Nikolai. A economia mundial e o imperialismo. São Paulo: Nova Cultural, 1986.

4. CAMILO, P. Desnacionalização e concentração da indústria láctea no Brasil. Anais do XI Encontro Nacional da ANPEGE. Presidente Prudente: UFGD Editora, 2015, p. 6130-6141.

5. CAMPOS, Fábio A.; SABADINI, Mauricio de S. Hilferding e o nexo imperialista entre capital financeiro e exportação de capital. Texto para Discussão. IE/Unicamp, Campinas, n. 243, ago. 2014.

6. CASTRO, Iná E. de. Análise geográfica e o problema epistemológico da escala. Anuário do Instituto de Geociências, Rio de Janeiro, v. 15, p. 21-25, 1992.

7. CHESNAIS, François. A mundialização do capital. São Paulo: Xamã, 1996.

8. CORRÊA, Domingos Sávio. Região, imperialismo e a recente onda de fusões e aquisições de empresas no Brasil. In: Anais do XI Encontro Nacional da ANPEGE. Presidente Prudente: UFGD Editora, 2015, p. 6154-6165.

9. CUNHA, R. C. Estruturas, estratégias de mercado e comercialização e fluxos de distribuição da soja no sul do Maranhão. Anais do XI Encontro Nacional da ANPEGE. Presidente Prudente: UFGD Editora, 2015, p. 6211-6222.

10. FARIAS, F. R. O cooperativismo agropecuário no Sul do Brasil. In. Anais do XI Encontro Nacional da ANPEGE. Presidente Prudente: UFGD Editora, 2015, p. 6104-6129.

11. FERREIRA, Lucas S. Geografia da recuperação argentina (2003-2015). Anais do XI Encontro Nacional da ANPEGE. Presidente Prudente: UFGD Editora, 2015, p. 1113-1126.

12. FREEMAN, C. Inovações e ciclos longos de desenvolvimento. Ensaios FEE, Porto Alegre, v. 5, n. 1, p. 5-20, 1984.

13. FREEMAN, C. The National system of Innovation in a historical perspective. Journal of Economics, Cambridge, v. 19, n. 1, p. 5-24, 1995.

14. FREEMAN, C. Technology policy and economic performance: lessons from Japan. London: Pinter Publishers, 1987.

15. GERMER, C. M. A irrelevância prática da agricultura 'familiar' para o emprego agrícola. Reforma Agrária, Campinas, v. 31, n. 1, jan./abr., 2002. p. 47-62.

16. GERMER, Claus M. O sistema de crédito e o capital fictício em Marx. Ensaios FEE, Porto Alegre, v. 15, n. 1, 1994, p. 179-201.

17. GONÇALVES, J. S. Carmas da questão agrária. Informações Econômicas, SP, v. 34, n. 7, jul. 2004. p. 41-4.

18. HILFERDING, R. O capital financeiro. São Paulo: Nova Cultural, 1985. 
19. HOBSON, John Atkinson. Estudio del imperialismo. Madrid: Alianza Editorial, 1981.

20. HUNTINGTON, Samuel. O choque de civilizações e a recomposição da ordem mundial. S. Paulo: Objetiva, 1997.

21. JESUS, G. V. A expansão urbana do Norte da Ilha de Santa Catarina. Anais do XI Encontro Nacional da ANPEGE. Presidente Prudente: UFGD Editora, 2015, p. 6303-6315

22. KANITZ, A. O parque tecnológico da Grande Florianópolis-SC: Parqtec Alfa: aplicação do modelo de William Bolton na sua organização. 1998. Dissertação (Mestrado em Geografia)UFSC, Florianópolis.

23. KANITZ, A. Parques tecnológicos e incubadoras constituídos no estado de Santa Catarina: um estudo Geográfico. 2013. Tese (Doutorado em Geografia)-UFSC, Florianópolis.

24. KAUTSKY, Karl. Ultra - imperialism. In: Die Neue Zeit. September 1914. Disponível em: < http://marxists.org/archive/kautsky/1914/09/ultra-imp.htm >. Acesso em: 10 mar. 2016.

25. KRUGMAN, Paul. Globalização e globobagens: verdades e mentiras do pensamento econômico. R. Janeiro: Campus, 1997.

26. LACERDA, Adriano C. Exportações do setor agroalimentar no Sul do Brasil: panorama atual. ENCONTRO NACIONAL DA ANPEGE, 11, 2015, Presidente Prudente. Anais do XI Encontro Nacional da ANPEGE. Presidente Prudente: UFGD Editora, 2015, p. 6176-6186.

27. LEFEBVRE, Henri. O pensamento de Lenine. Lisboa: Moraes Ed. 1969.

28. LENIN, V. I. Imperialismo, estágio superior do capitalismo: ensaios. São Paulo: Expressão Popular, 2012.

29. LÊNIN, V. I. Quem são os "amigos do povo" e como lutam contra os social-democratas. Obras escolhidas. Rio de Janeiro: Editora Vitória, 1955.

30. LEFEBVRE, Henri. O pensamento de Lenine. Lisboa: Moraes Ed. 1969.

31. LIST, F. Sistema nacional de economia política. São Paulo: Editora Abril Cultural, 1983.

32. LOSURDO, D. Liquidar o monopólio ocidental da tecnologia é também luta revolucionária Entrevista a Tian Shigang em dez de 2011. Disponível em: <http://resistir.info/losurdo/ losurdo_15dez11.html>. Acesso em: 16 mar. 2016.

33. LUXEMBURG, Rosa. A acumulação do capital: contribuição ao estudo econômico do imperialismo. São Paulo: Nova Cultural, 1985.

34. MAMIGONIAN, Armem. Apresentação. In: JABBOUR, Elias. China: infra-estrutura e crescimento econômico. S. Paulo: Anita Garibaldi, 2006, p. 7-10.

35. MAMIGONIAN, Armen. Tecnologia e Desenvolvimento Desigual no Centro do Sistema Capitalista. Revista do Centro de Ciências Humanas, Florianópolis, n. 2, CCH/UFSC, 1982.

36. MARX, K. O Capital. v. 2, Livro 2. São Paulo: Abril Cultural. 1984.

37. MEDEIROS, Marlon C. Estado, capital financeiro e agricultura no Brasil atual. Anais do XI Encontro Nacional da ANPEGE. Presidente Prudente: UFGD Editora, 2015, p. 6223-6232. 
38. MORAES, Edson M. Evolução do comércio marítimo internacional com base a teoria dos ciclos longos de Kondratieff. Anais do XI Encontro Nacional da ANPEGE. Presidente Prudente: UFGD Editora, 2015, p. 6340-6351.

39. NAVARRO, Z. Agricultura Familiar no Brasil: entre a política e as transformações da vida econômica. In: A Agricultura Brasileira. Brasília: IPEA, 2010, p. 185-209.

40. NORTH, D. Custos de transação, instituições e desempenho econômico. Rio de Janeiro: Instituto Liberal, 1994.

41. OTREMBA, Erich. Geografía general del comercio y de lãs comunicaciones. Barcelona: Ediciones Omega, 1959.

42. PADILHA, W. Prodecoop e Procap-agro e o crescimento das cooperativas agroindustriais da Região Sul. Anais do XI Encontro Nacional da ANPEGE. Presidente Prudente: UFGD Editora, 2015, p. 6187-6198.

43. PRESTES, Elisa G. China e Brasil: aproximações e distanciamentos. Anais do XI Encontro Nacional da ANPEGE.Presidente Prudente: UFGD Editora, 2015, p. 6270-6281.

44. RATZEL, Friedrich. El território, la sociedad y el Estado. In: MENDONZA, Josefina G. et al (Ed.). El pensiamento geográfico. Madrid: Alianza, 1982, p. 193-203.

45. RODRIGUES Sunamita I.; FERNANDES Ana C. de A. Sistema Territorial de Inovação: indícios da importância da dimensão espacial para os processos inovativos. Anais do XI Encontro Nacional da ANPEGE.Presidente Prudente: UFGD Editora, 2015, p. 6316-6327.

46. ROSA, H. R. Indústria brasileira e a emergente Divisão Internacional do Trabalho (DIT): desafios da indústria brasileira de calçados a luz da crise mundial de 1973. Anais do XI Encontro Nacional da ANPEGE. Presidente Prudente: UFGD Editora, 2015, p. 6282-6293.

47. ROSENBERG, Nathan; FRISCHTAK, Cláudio R. (1983) Inovação Tecnológica e Ciclos de Kondratiev. Pesquisa e Planejamento Econômico, Rio de Janeiro, v. 13, n. 3, 1983.

48. SANTOS, E. F. Análise da política de arranjos produtivos locais (APLs) implantada em Alagoas. Anais do XI Encontro Nacional da ANPEGE. Presidente Prudente: UFGD Editora, 2015, p. 6166-6175.

49. SANTOS, M; SILVEIRA, M. L. O Brasil: território e sociedade no início do século XXI. Rio de Janeiro: Record, 2001.

50. SANTOS, M. A natureza do espaço: técnica e tempo, razão e emoção. São Paulo: Edusp, 2009.

51. SANTOS, M. Técnica, espaço, tempo: globalização e meio técnico-cientifico-informacional. São Paulo: Hucitec, 1996.

52. SANTOS, M. Espaço e sociedade. 2. ed. Petrópolis: Vozes, 1982.

53. SCHATZ, Patrícia V. O espetáculo dos gramados: discursos pela financeirização do futebol brasileiro e a transformação da prática esportiva em mercadoria. Anais do XI Encontro Nacional da ANPEGE. Presidente Prudente: UFGD Editora, 2015, p. 6294-6302.

54. SCHUMPETER, J. A. Capitalismo, socialismo e democracia. Rio de Janeiro: Zahar. 1984. 
55. .Teoria do desenvolvimento econômico. São Paulo: Abril Cultural, 1985.

56. . Imperialismo e classes sociais. Rio de Janeiro: Zahar Editores, 1961.

57. SERENI, E. La categoria de Formación Económico-social. Cuadernos de Passado y Presente, Cordoba, Argentina: Siglo XXI. 1976.

58. SILVA J. G. A expansão da rede federal de educação profissional, cientifica e tecnológica na região Sul do Brasil. Anais do XI Encontro Nacional da ANPEGE.Presidente Prudente: UFGD Editora, 2015, p. 11150-11162.

59. SOARES, P. T. P. S. Questionando o questionamento aos clássicos do marxismo sobre a agricultura. SEP, 1999.

60. SUERTEGARAY, D. M. A. O atual e as tendências do ensino e da pesquisa em geografia no Brasil. Revista do Departamento de Geografia (USP), São Paulo, v. 16, p. 38-45, 2005.

61. SUERTEGARAY, D. M. A. Rumos e rumores da pós-graduação e da pesquisa em geografia no Brasil. Revista da ANPEGE, v. 3, p. 15-30, 2007.

62. SUZIGAN, W.; ALBUQUERQUE, E. M. A interação entre universidades e empresas em perspectiva histórica no Brasil. Texto de Discussão, Belo Horizonte, n. 329, 2008.

63. TIGRE, P. B. Inovação e teorias da firma em três paradigmas. Revista de Economia Contemporânea, Rio de Janeiro, n. 3, 1998.

64. VASCONCELOS JR, N. A. Organização espacial da produção leiteira de Alagoas: caracterização da cadeia de laticínios no semiárido. Anais do XI Encontro Nacional da ANPEGE. Presidente Prudente: UFGD Editora, 2015, p. 6199-6210.

65. VEBLEN, T. A teoria da classe ociosa: um estudo econômico das instituições. São Paulo: Abril Cultural. 1985.

66. VIDAL DE BLACHE, Paul. Princípios de geografia humana: a marcha da humanidade. Lisboa: Cosmos, 1954.

67. WENNING, Emanuela F. Intra-centralidades urbanas no município de Blumenau-SC. Anais do XI Encontro Nacional da ANPEGE.Presidente Prudente: UFGD Editora, 2015, p. 6245-6256.

68. ZEFERINO, Mariana B. Revitalização do sistema portuário brasileiro e revalorização da cabotagem no Brasil. Anais do XI Encontro Nacional da ANPEGE. Presidente Prudente: UFGD Editora, 2015, p. 6328-6339.

Artigo recebido em 28 de março de 2016.

Artigo aceito em 28 de abril de 2016. 